\title{
Heterorhadbitis indica SL0708 hermaphrodite and axenic egg isolation
}

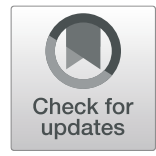

\author{
N. Porras and A. Sáenz-Aponte*
}

\begin{abstract}
In Colombia, Heterorhabditis indica SL0708 is an entomopathogenic nematode (EPN) used for effective biological control of insect pests. The purpose of this study was to standardize hermaphrodite and axenic egg extraction, in addition to describe egg developmental stages to optimize in vitro infective juvenile egg production for future pest control. Thus, the greater wax moth, Galleria mellonella L. (Lepidoptera: Pyralidae), in its last larval instar was dissected at 90, 95, 100, 105, 110, and $115 \mathrm{~h}$ post-infection. Hermaphrodites were counted and egg stage within the uterus was characterized. Fertilized H. indica SL0708 egg presented 9 developmental stages; stage 1: maternal pronucleus migrates to the posterior pole, forming pseudoclivage segmentation until reaching stage 9 with a moving $\mathrm{J} 1$ formed. At $95 \mathrm{~h}$ post-infection, the greatest number of hermaphrodites, at stage 9 , was observed. Not all hermaphrodites presented the same number of eggs and stage of development within their uterus. Subsequently, a protocol to rupture hermaphrodites and sterilize eggs was evaluated, assaying three different exposure times and two egg incubation periods. A hermaphrodite exposure to $0.1 \mathrm{M} \mathrm{NaOH}$ and $1 \% \mathrm{NaOCl}$ solution for 15 min to allow obtaining viable axenic eggs, facilitating laboratory tests with nematode H. indica SL0708 free of Photorhabdus luminescens SL0708 or other bacteria that could introduce variability in future assays was established.
\end{abstract}

Keywords: Entomopathogenic nematode, Heterorhabditis indica, Infective juvenile stage, Developmental stages, Fertilization

\section{Background}

The entomopathogenic nematode, Heterorhabditis indica SL0708 is a eumetazoan, ecdysozoan protostomate, and an obligate and lethal parasite of insects, as a consequence of its symbiotic association with enteric bacteria that kill the insect host. Fertilization occurs in hermaphrodite adults, with sperm and eggs generated in the ovotestis. $H$. indica SL0708 is protoandrous, namely, sperm is produced before eggs, resulting in self-fertilization (Johnigk and Ehlers 1999a, b and Sáenz and Lopez 2011). Eggs are isolecithal, with sparse evenly distributed yolk. $H$. indica SL0708 exhibits rotational holoblastic egg cleavage, in an asymmetric fashion along the anterior-posterior axis, near of what is to become the posterior pole. During early cleavage, each asymmetrical division results in a large $A B$ founder cell, with a smaller posterior stem cell of P1 lineage. During the second division, $\mathrm{AB}$ founder cell

\footnotetext{
* Correspondence: adriana.saenz@javeriana.edu.co

Laboratory for Biological Control, Biología de Plantas y Sistemas Productivos, Departamento de Biología, Pontificia Universidad Javeriana, Bogotá 110561,
} Colombia

cleavage occurs equatorially, producing another EMS founder cell, while the stem cell divides meridionally to produce a posterior P2 stem cell (Skop and White 1998 and Gilbert, Gilbert F 2014). Following cleavage stages, a juvenile one (J1) results.

Axenic J1 is a developmental stage, used as an alternative to inoculate in vitro solid or liquid $H$. indica SL0708 production media, where $P$. luminescens subsp. akhurstii SL0708 bacterial symbiont was first added into the culture media (Salazar et al. 2017). Bacteria are transformed by the culture media and used as a source of nourishment for J1 (Lunau et al. 1993 and Ehlers 2001). Nevertheless, given the difficulty in recovering viable $\mathrm{J} 1$, generally in vitro production media inoculation processes use infective juvenile (IJ). However, if these IJ are not axenic, without superficial microorganisms or between their cuticles, changes in P. luminescens SL0708 concentration in the media makes standardization and process development more cumbersome. Presence of a microorganism different from the symbiont, such as Ochrobactrum spp., Providencia spp., and Paenibacillus 
spp., can reduce IJ production yield and/or inhibit the nematodes' life cycle (Jackson et al. 1995; Boemare et al. 1996; Babic et al. 2000 and Enright and Griffin 2004).

Therefore, studies have been developed to determine protocols for axenic egg harvest, as described by Poinar JR G (1979), involving chemicals and antibiotics. Lunau et al. (1993) described two methodologies: alkaline lysis and surface sterilization for Steinernema and Heterorhabditis species. With this methodology, it was possible to obtain bacteria-free eggs, particularly of Steinernema genus. Later, Kaya and Stock (1997) described a protocol based on mechanical maceration and chemicals to rupture hermaphrodites. Recently, Susurluk et al. (2013) adapted and implemented the methodology described by Lunau et al. (1993) for Heterorhabditis bacteriophora isolated in Turkey to evaluate nematode quality produced in vitro.

Henceforth, this study standardized H. indica SL0708 hermaphrodite isolation to obtain axenic viable eggs followed by their development.

\section{Materials and methods \\ Heterorhadbitis indica SL0708 hermaphrodite quantification and egg isolation}

Last larval instar of Galleria mellonella L. (Lepidoptera: Pyralidae) larvae $(n=160)$ was infected in multi-well plates, inoculating $50 \mathrm{IJs} /$ larvae and incubated at $26^{\circ} \mathrm{C}$ for $90,95,100,105,110$ and $115 \mathrm{~h}$. For nematode development identification, 10 larvae were dissected at different post-infection time points to classify as egg, JI, J1, J2, J3, J4, hermaphrodite, adult hermaphrodite, Endotokia matricida, female, or male. For $H$. indica SL0708 egg development nine stages were recognized, with a stage 1 the least developed, identified as ruffling, and stage 9 was the most developed, with a formed and moving J1within the egg. Other stages were stage 2, pseudoclivage; stage 3 , pronuclei fusion; stage 4 , two cell formation; stage 5, initiation of four cell development; stage 6, four cell development; stage 7, gastrulation; and stage 8 , morphogenesis.

To determine the total number of eggs and egg percentage at stage 9 within a hermaphrodite from $1 \mathrm{G}$. mellonella larva, $10 \mathrm{H}$. indica SL0708 hermaphrodites were isolated. Each hermaphrodite was individually macerated. From the obtained suspension, six $30 \mu \mathrm{l}$ drops were obtained for egg quantification.

\section{H. indica SL0708 J1 viable axenic egg isolation}

Protocols from Lunau et al. (1993), Kaya and Stock (1997), and Susurluk et al. (2013) were implemented to obtain axenic eggs. Thirty hermaphrodites were exposed to $0.1 \mathrm{M} \mathrm{NaOH}$ and $1 \% \mathrm{NaClO}$ for 5,10 , and $15 \mathrm{~min}$, followed by 3 -min centrifugation at $3000 \mathrm{rpm}$. The supernatant was discarded, and a $\mathrm{dH}_{2} \mathrm{O}$ was washed, followed by centrifugation. The number of eggs in stage 9 was estimated.

Following sterilization to determine J1 egg axenia state and viability, eggs were seeded into trypticase soy broth (TSB) and incubated for 24 to $48 \mathrm{~h}$ at $26^{\circ} \mathrm{C}$. After each incubation period, the number of $\mathrm{J} 1$ present in the media was determined and seeded into NBTA agar (0.04 g trifenyltetrazolium chloride TTC, $0.025 \mathrm{~g}$ bromothymol blue (BTB), $20 \mathrm{~g}$ nutritive agar/L) by streaking media and incubated at $26^{\circ} \mathrm{C}$ for $72 \mathrm{~h}$ to determine Photorhabdus luminescens subsp. akhurstii SL0708 symbiont bacteria presence of or other bacteria.

\section{Statistical analysis}

A completely random assay was performed, using $10 \mathrm{G}$. mellonella larvae for each treatment and 3 replicates in time for isolation assay and hermaphrodite appearance. The independent variable corresponded to G. mellonella post-infection time $90,95,100,105,110$, and $115 \mathrm{~h}$, and the dependent variable to the total hermaphrodite number and egg developmental stage.

For egg and J1 isolation methodology, a completely random assay was performed including three treatments with three replicates in time. To determine the number of obtained J1 after egg sterilization, data with exposure and incubation time were compared ( 24 and $48 \mathrm{~h}$ ). To facilitate axenic egg statistical analysis, the absence of bacterial growth was designated as 1, and bacterial growth in NBTA media as 2. A one-way ANOVA was performed with the significance level of $0.05 \%$. To determine where differences occurred between groups, a Tukey post hoc test was performed, using SPSS Statistics V 24.0 (IBM, Corporation, Armonk, NY, USA).

\section{Results and discussion}

\section{$H$. indica SL0708 hermaphrodite quantification and egg} development characterization

The largest hermaphrodite population was obtained at $105 \mathrm{~h}$ (31 hermaphrodites) and $115 \mathrm{~h}$ (24 hermaphrodites) (Fig. 1) with significant differences post-infection $(P=0.001, \mathrm{df}=5, F=16.969)$. Egg stage within hermaphrodite uterus isolated at 105 and $115 \mathrm{~h}$ corresponded to stages 6 and 8, respectively (Figs. 2 and 3f, h).

Regarding egg maturation within the hermaphrodite uterus, significant differences were observed at the six different post-infection times evaluated, with eggs at stage 9 in the vicinity of the vagina at $95 \mathrm{~h}$ post-infection (Figs. 2 and 3i). For the six time points, evaluated eggs were between developmental stages 5 and 9 (Fig. 2).

The nine stages of egg cleavage were observed within $H$. indica SL0708 uterus. For the first stage, maternal pronucleus migrated to the posterior pole, forming a pseudoclivage furrow (Fig. 3a). Subsequently, the maternal pronucleus met the paternal pronucleus and jointly 


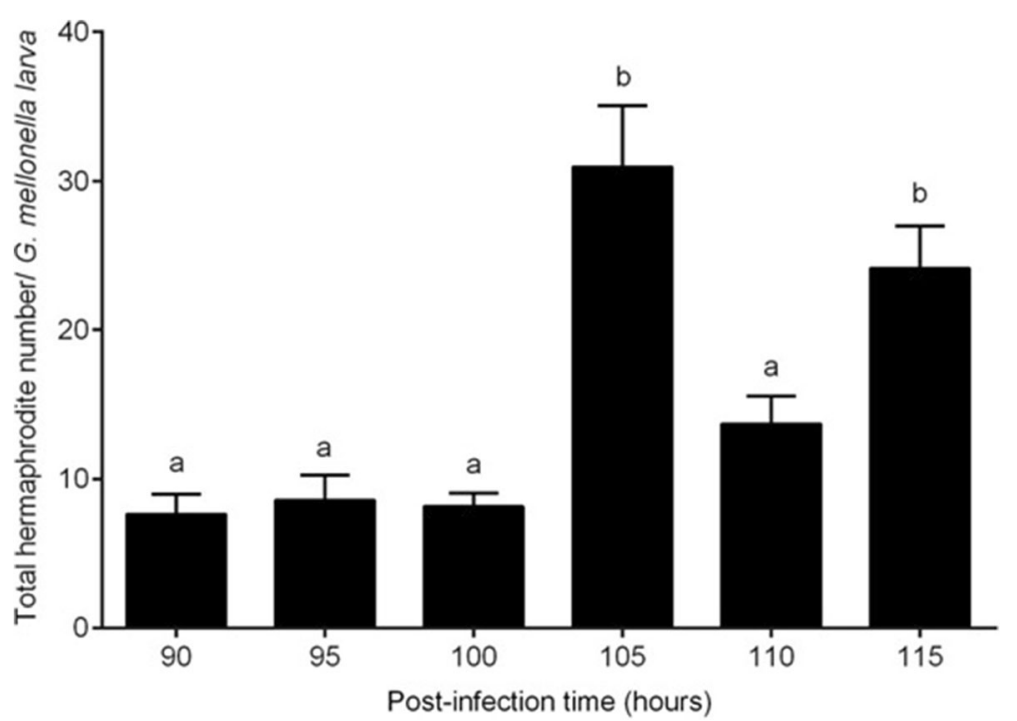

Fig. 1 Heterorhabditis indica SL0708 hermaphrodites isolated at six different post-infection time points. Significant differences $(p<0.05)$ among times were established by Tukey post hoc tests and are represented by different letters among times. Mean \pm SEM, $(n=30)$

migrated to the anterior pole (3B), where pronuclei fusion occurred (Fig. 3c). Forty minutes post-fertilization, first division took place forming two cells: $\mathrm{AB}$ and $\mathrm{P} 1$ (Fig. 3d). Later $A B$ and P1 initiated their division to form 4 cells: ABa, ABp, EMS, and P2, respectively (Fig. 3e-f). Subsequent divisions occurred in the proximity of the vulva, where gastrulation took place (Fig. $3 g$ ), producing approximately 30 cells. These cells elongated and invaginated, resulting in $\mathrm{J} 1$ development (Fig. 3h). At $95 \mathrm{~h}$ post-fertilization, $H$. indica SL0708 J1 was observed moving within the egg (Fig. 3i).
For the six post-infection time points evaluated, in addition to observing hermaphrodites with their eggs at different stages developmental stages (1-9) (Fig. 3), individuals in Endotokia matricida were found. The greatest number of hermaphrodites was isolated at (105 and 115 h) post-infection.

The presence of hermaphrodites in Endotokia matricida have been possibly related to hermaphrodite's incapability of laying adult eggs, since no muscular contraction of the vulva occurred, allowing for opening and egg release. Additionally, many eggs were laid at the

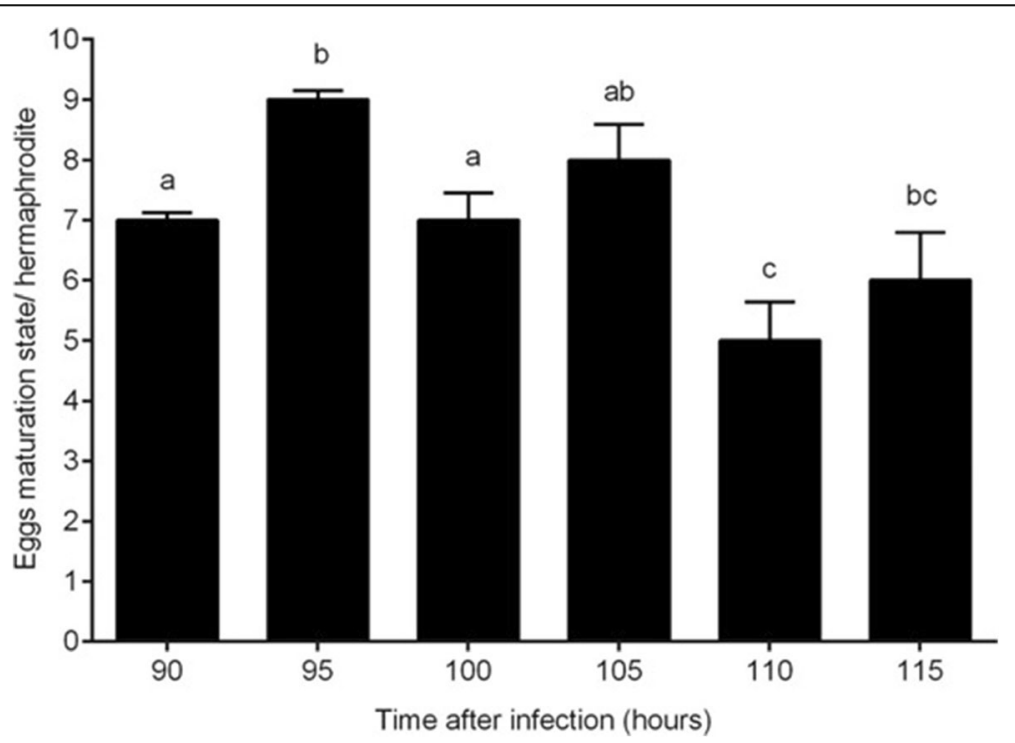

Fig. 2 Egg maturation stages isolated from H. indica SL0708 uterus. Significant differences $(p<0.05)$ among times were established by Tukey post hoc tests and are represented by different letters among times. Mean \pm SEM, $(n=10)$ 


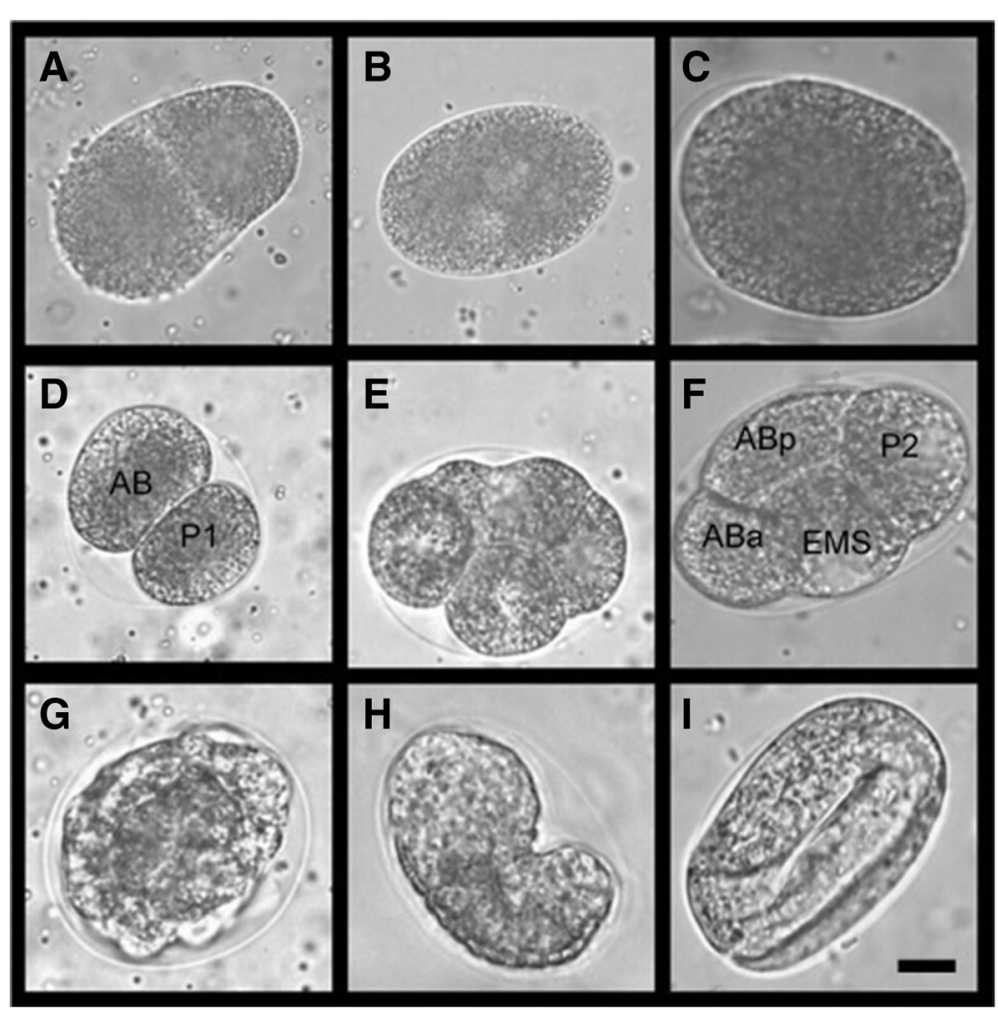

Fig. 3 H. indica SL0708 egg developmental stages. a Stage 1. b Stage 2. c Stage 3. d Stage 4. e Stage 5. f Stage 6. g Stage 7. h Stage 8. i Stage 9. (Scale bar $=10 \mu \mathrm{m}$ )

same time, approximately 22 to $24 \mathrm{~h}$ post-fertilization. However, there was a time-lapse, where no egg laying occurred. Therefore, some eggs could have remained within the hermaphrodite and hatched within the uterus (Johnigk and Ehlers 1999a, b).

On the other hand, H. indica SL0708 eggs must be extracted at stage 9, given if they are extracted at earlier times the egg does not fully develop and no J1 hatches. After the eggs are fertilized, they locate themselves in the center of the uterus, where they undergo development of their first six stages. Later, they move close to the vulva, where gastrulation, morphogenesis, and J1 take place within the egg. This is a biologically relevant condition when entomopathogenic nematodes are produced in vitro. Furthermore, in some cases, not all fertilized eggs hatch, given the force vulva contraction exerts, when eggs are laid, which can result in egg rupture and J1 death (Lunau et al. 1993; Bucher and Seydoux 1994 and Johnigk and Ehlers 1999a, b).

The huge amount of hermaphrodites found at 105 and $115 \mathrm{~h}$ could be related to IJ invasion percentage, which was greatest at these hours (61.9 and 48.3\%), respectively. Henceforth, not all IJs can enter G. mellonella larvae, and those that can achieve it at different times, even if they are exposed to the host at the same time and under the same conditions. These differences are due to signals released from the host, such as feces and $\mathrm{CO}_{2}$ that must be detected by $H$. indica SL0708 IJ. The IJ can then move until it localizes the host.

H. indica SL0708 hermaphrodite at $95 \mathrm{~h}$ post-infection had in its uterus 835 eggs (641-1116). Only 9.7\% of them were in stage 9, i.e., 81 eggs $(58-108)$ (Fig. 3i). Therefore, $81.3 \%$ were at earlier stages, before J1 was completely formed (Fig. 3). Variability in egg number and developmental stage was likely associated with uterus size and hermaphrodite physiological maturation (Han and Ehlers 1998).

In the uterus of a single H. indica SL0708 hermaphrodite, it is possible to find more than one egg developmental stage related to the process of fertilization. For fertilization to take place, first sperm has to be generated, which is stored in the receptaculum seminis. Germ cells that do not differentiate into sperm start oogenesis during the second meiotic division. Eggs mobilize from the ovotestis to the center of the uterus, going through the receptaculum seminis, where fertilization takes place. Thus, not all eggs are fertilized at the same time. Moreover, less mature eggs cannot be fertilized, since sperm is limited (Barlow et al. 2007).

\section{H. indica SL0708 J1 axenic viable egg isolation}

After performing hermaphrodite rupture and sterilization protocols, eggs were counted. Significant differences for 


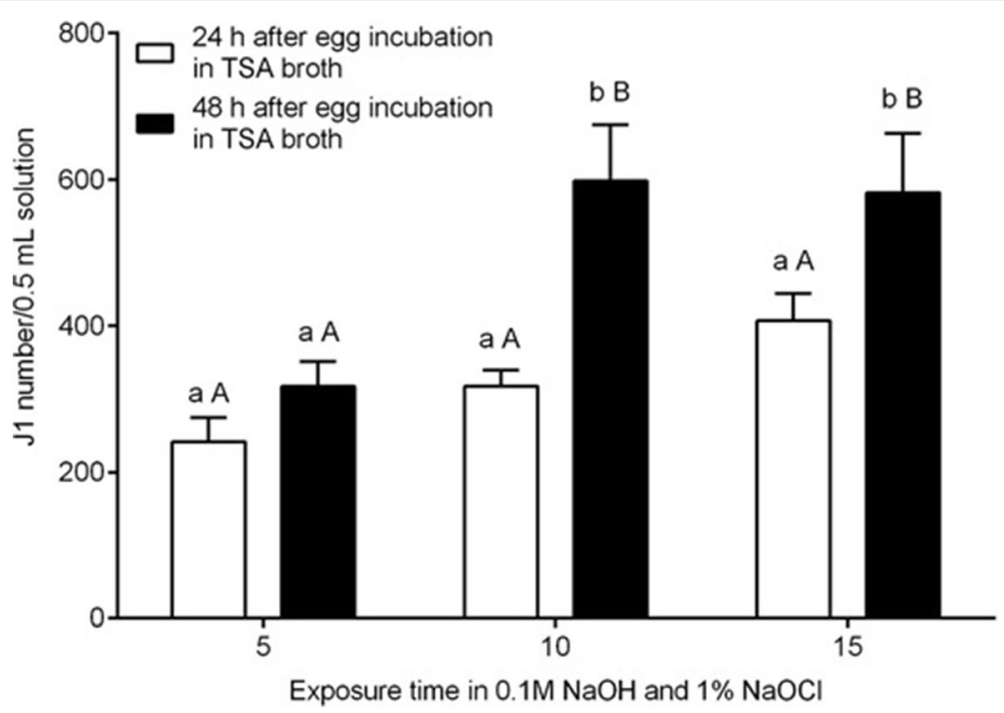

Fig. 4 Viable H. indica SL078 J1 s quantification. Significant differences among J1s at three exposure times (lowercase letters) and two incubation times (uppercase letters) were established by Tukey post hoc tests $(p<0.05)$. Mean \pm SEM $(n=30)$

viable $\mathrm{J} 1 \mathrm{~s}$ were observed among treatments with $0.1 \mathrm{M}$ $\mathrm{NaOH}$ and $1 \% \mathrm{NaOCl}(P=0.001, \mathrm{df}=2 F=9.515)$ and incubation times $(P=0.001, \mathrm{df}=1, F=16.866)$ (Fig. 4). After $48 \mathrm{~h}$ of egg incubation, the largest number of J1 was obtained at $10 \mathrm{~min}(598 \mathrm{~J} 1 \mathrm{~s})$, followed by $15 \mathrm{~min}(582 \mathrm{~J} 1 \mathrm{~s})$ of exposure. Hatching percentage ranged between 23.9 and $24.6 \%$ of total eggs obtained from $30 \mathrm{H}$. indica SL0708 hermaphrodites at $95 \mathrm{~h}$ post-infection.

Hermaphrodite rupture and egg sterilization were achieved since $\mathrm{NaOH}$ hydrolyses collagen. On the other hand, $\mathrm{NaOCl}$ breaks down sulfhydryl bonds in the cuticle, responsible for stabilization and resistance. In addition, it eliminates bacteria associated with the chorion of the egg, since it is an alkaline solution and disrupts bacterial cytoplasmic membrane stability. Furthermore, it inhibits enzyme activity associated with trans-membrane proteins, resulting in biosynthesis alterations and phospholipid degradation (Lee 1966; Estrella et al. 2002 and Quintero and Zapata 2017).

Regarding bacterial growth, significant differences were observed for the three exposure times evaluated $(P=0.008$, $\mathrm{df}=2 ; F=5.133)$. However, no differences were detected for incubation time $(P=0.110, \mathrm{df}=1, F=2.619)$. The least growth for P. luminescens subsp. akhurstii SL0708 was determined at $15 \mathrm{~min}$. Therefore, the time with the most viable and axenic $\mathrm{J} 1$ was at $15 \mathrm{~min}$ treatment with $0.1 \mathrm{M}$ $\mathrm{NaOH}$ and $1 \% \mathrm{NaOCl}$ solution, evidenced in TSA media.

\section{Conclusions}

According to the obtained results with $H$. indica SL0708 isolation, it is possible to isolate the most numbers of hermaphrodites with eggs at stage 9 at $95 \mathrm{~h}$ post-infection. However, not all hermaphrodites present the same number of eggs or stage of maturation within the uterus. Evidencing nine stages of embryonic development until it reaches J1 stage. In addition, hermaphrodite exposure to $0.1 \mathrm{M} \mathrm{NaOH}$ and $1 \% \mathrm{NaOCl}$ solution allowed to obtain axenic and viable eggs, which can facilitate laboratory assays, where the nematode is required free from $P$. luminescens subsp. akhurstii SL0708 or other associated bacteria.

\section{Acknowledgements}

The results obtained were within the Project: Producción in vitro y criopreservación del nematodo entomopatógeno Heterorhabditis sp. SL0708 (Rhabditida: Heterorhabditidae), grant No. 6649, financed by Pontificia Universidad Javeriana. The authors also thank Pontificia Universidad Javeriana for financial support for this publication grant No. 7025.

\section{Funding}

This study is part of the project "Producción in vitro y criopreservación del nematodo entomopatógeno Heterorhabditis sp. SL0708 (Rhabditida: Heterorhabditidae).

Availability of data and materials

All data of the study have been presented in the manuscript, and the materials, which are used in this study, are of high quality and grade.

\section{Authors' contributions}

NP carried out the laboratory work, performed the statistical analysis, and drafted the manuscript. ASA assisted in designing the experiments, and accomplished overall supervision and coordination of laboratory work, results analysis, and manuscript drafting. All authors read and approved the final manuscript.

Ethics approval and consent to participate Not applicable for that section.

Consent for publication

Not applicable for that section.

Competing interests

The authors declare that they have no competing interests. 


\section{Publisher's Note}

Springer Nature remains neutral with regard to jurisdictional claims in published maps and institutional affiliations.

Received: 13 August 2018 Accepted: 21 March 2019

Published online: 08 April 2019

\section{References}

Babic I, Saux MF, Giraud E, Boemare N (2000) Ocurrence of natural dixenic associations between the symbiont Photorhabdus luminescens and bacteria related to Ochrobactrum spp. in tropical entomopathogenic Heterorhabditis spp. (Nematoda, Rhabditida). Microbiology 146:709-718

Barlow D, Cline T, Hodgkin J, Whitaker M (eds) (2007) Principios del desarrollo. L Wolpert, España

Boemare N, Laumond C, Mauleon H (1996) The entomopathogenic nematodebacterium complex: biology, life cycle and vertebrate safety. Biocontrol Sci Tech 6:333-345

Bucher EA, Seydoux G (1994) Gastrulation in the nematode Caenorhabditis elegans. Semin Cell Dev Biol 5:121-130

Ehlers R-U (2001) Mass production of entomopathogenic nematodes for plant protection. Appl Microbiol Biotechnol 56:623-633

Enright MR, Griffin CT (2004) Specificity of association between Paenibacillus spp. and the entomopathogenic nematodes, Heterorhabditis spp. Microb Ecol 48: $412-421$

Estrella C, Estrella CRA, Barbin EL, Spanó JC, Marchesan MA, Pecóra JD (2002) Mechanism of action of sodium hypochlorite. Braz Dent J 13:113-117

Gilbert F S (2014) Developmental biology. Swarthmore College, Swarthmore

Han RC, Ehlers RU (1998) Cultivation of axenic Heterorhabditis spp. dauer juvenilees and their responde to non-specific Photorhabdus luminescens food signals. Nematologica 44:425-435

Jackson TJ, Wang H, Nugent MJ, Griffin CT, Burnell AM, Dowds BCA (1995) Isolation of insect pathogenic bacteria, Providencia rettgeri, from Heterorhabditis spp. J Appl Bacteriol 78:237-244

Johnigk SA, Ehlers RU (1999a) Juvenile development and life cycle of Heterorhabditis bacteriophora and H. indica (Nematoda: Heterorhabditidae). Nematology 1:251-260

Johnigk SA, Ehlers RU (1999b) Endotokia matricida in hermaphrodites of Heterorhabditis spp. and the effect of the food supply. Nematology 1:717-726

Kaya HK, Stock SP (1997) Manual of techniques in insect pathology. A L Lawrence

Lee DL (1966) The structure and composition of the helminth cuticle. Adv Parasitol 4:187-254

Lunau S, Stoessel S, Schmidt-PEISKER AJ, Ehlers RU (1993) Establishment of monoxenic Inocula for scaling up in vitro cultures of the entomopathogenic nematodes Steinernema spp. and Heterorhabditis spp. Nematologica 39:385-399

Poinar JR G O (1979) Nematodes for biological control of insects. In: Boca Raton. C.R.C, Florida

Quintero J, Zapata JE (2017) Optimización de la extracción del colágeno soluble en ácido de subproductos de tilapia roja (Oreochromis spp.) mediante un diseño de superficie de respuesta. Inf tecnol 28:109-120

Sáenz A, Lopez JC (2011) Ciclo de vida y patogenicidad del aislamiento nativo Heterorhabditis sp. SL0708 (Rhabditida: Heterorhabditidae). Rev Colomb Entomol 37:43-47

Salazar J, Castiblanco A, Rodriguez Bocanegra M, Teran W, Sáenz Aponte A (2017) Photorhabdus luminescens subsp. akhurstii SL0708 pathogenicity in Spodoptera frugiperda (Lepidoptera: Noctuidae) and Galleria mellonella (Lepidoptera: Pyralidae). J Asia Pac Entomol 20:1112-1121

Skop AR, White JH (1998) The dynactin complex is required for cleavage plane specification in early Caenorhabditis elegans embryos. Curr Biol 8:1110-1116

Susurluk Al, Kongu Y, Ulu TC (2013) Quality control of in vitro produced Heterorhabditis bacteriophora (Rhabditida: Heterorhabditidae) strains isolated from Turkey. Turk Entomol Derg-tu 37:283-291

\section{Submit your manuscript to a SpringerOpen ${ }^{\circ}$ journal and benefit from:}

- Convenient online submission

- Rigorous peer review

- Open access: articles freely available online

- High visibility within the field

- Retaining the copyright to your article

Submit your next manuscript at $\boldsymbol{\nabla}$ springeropen.com 